\title{
Symptomatic Dystonias Associated with Structural Brain Lesions: Report of 16 Cases
}

\author{
Vladimir S. Kostic, Marina Stojanovic-Svetel and Aleksandra Kac̆ar
}

\begin{abstract}
Background: Symptomatic (secondary) dystonias associated isolated lesions in the brain provide insight into etiopathogenesis of the idiopathic form of dystonia and are a basis for establishing the possible correlation between the anatomy of a lesion and the type of dystonia according to muscles affected. Methods: In 358 patients with differently distributed dystonias, a group of 16 patients (4.5\%) was encountered in whom dystonia was associated with focal brain lesions. Results: Of the 16 patients, 3 patients had generalized, 3 segmental and 4 hemidystonia, while the remaining 6 patients had focal dystonia. The most frequent etiologies were infarction in 7 , and tumor in 4 patients. These lesions were usually found in the lenticular and caudate nucleus, thalamus, and in the case of blepharospasm in the upper brainstem. Conclusions: Our results support the suggestion that dystonia is caused by a dysfunction of the basal ganglia.
\end{abstract}

RÉSUMÉ: Dystonies symptomatiques associées à des lésions structurales du cerveau: à propos de 16 cas. Introduction: Les dystonies symptomatiques (secondaires) associées à des lésions cérébrales isolées aident à comprendre la pathogenèse de la forme idiopathique de dystonie et servent de base à une corrélation éventuelle entre la topographie de la lésion et le type de dystonie, selon sa distribution. Méthodes: Parmi 358 patients atteints de dystonies à distribution variée, nous avons étudié un groupe de 16 sujets $(4.5 \%)$ chez qui la dystonie était associée à des lésions focales du cerveau. Résultats: De ces 16 patients, 3 présentaient une dystonie généralisée, 3 présentaient une dystonie segmentaire, 4 présentaient une hémidystonie et les 6 autres présentaient une dystonie focale. L'étiologie la plus fréquente était un infarctus, chez 7 patients, ou une tumeur, chez 4 patients. Ces lésions se situaient le plus souvent dans les noyaux lenticulaire et caudé, le thalamus, et, dans le cas du blépharospasme, dans la partie supérieure du tronc cérébral. Conclusion: Nos résultats appuient la notion que la dystonie est la conséquence d'une dysfonction au niveau du noyau lenticulaire, du noyau caudé, de l'avant-mur ou du noyau amygdalien.

Can. J. Neurol. Sci. 1996; 23: 53-56

Idiopathic (primary) dystonia is a disorder characterized by involuntary sustained muscle contractions which cause repetitive movements, twisting and abnormal postures, without other neurological features. ${ }^{1}$ Although progress has been made ${ }^{2}$ the pathological, biochemical and physiological mechanisms of idiopathic dystonia have not been fully characterized. ${ }^{3}$ Symptomatic (secondary) dystonias comprise these cases secondary to brain injury or other diseases. 4

Symptomatic dystonias which are related to isolated lesions in the brain enable insight into etiopathogenesis of the disease and provide a basis for correlation of topography of lesions and type of dystonia according to muscle affected. ${ }^{3,4}$

In this study we present a personal series of 16 patients with dystonic movements associated with neuroradiologically-verified focal brain lesions for correlation of the distribution of dystonia with location of lesion.

\section{Patients and Methods}

The studied group included patients with symptomatic dystonia who fulfilled the following criteria: (1) presence of dystonia (focal, segmental, generalized, hemidystonia); (2) normal childbirth and early psychomotor development; (3) negative history of exposure to drugs and toxins; (4) absence of metabolic and degenerative disorders which may induce dystonia, and (5) neuroradiologically-evidenced anatomic lesions which are correlated with and/or have acceptable temporal relation to dystonic manifestations.

From 358 patients with differently distributed dystonias treated at the Institute for Neurology CCS, Belgrade, in the period October 1987 - May 1994, 16 patients (4.5\%) fulfilled the above criteria. In the remaining 342 patients focal lesions were absent (cortical atrophy was not accepted as a relevant lesion). Considering the paucity of neurological findings

From the Institute for Neurology CCS. Belgrade, Yugoslavia.

RECEIVED JANUARY 2, 1995. ACCEPTED IN FINAL FORM OCTOBER 11. 1995.

Reprint requests to: Vladimir S. Kostit, MD, Institute for Neurology CCS, ul. dr Subotica 6. 11000 Belgrade. Yugoslavia. 
described following discrete lesions in the caudate, ${ }^{5}$ two patients (one with oromandibular dystonia and one with adductor spasmodic dysphonia) with small unilateral infarcts in this region, but lacking a definite temporal relation between the infarction and dystonia, were not included. After detailed history and neurological examination the diagnosis of dystonia was established by 2 neurologists independently (V.S.K. and M.S.). Following this laboratory, neuropsychological and neuroradiological studies (CT and/or MRI) were conducted, as recommended for the investigation of dystonia. ${ }^{1}$

\section{Results}

The clinical characteristics of the 16 patients with focal brain lesions are summarized in Table 1. The mean age at onset of dystonic movements in our patients ( 8 females and 8 males) was 45 years (range from 19 to 69 years), with the mean duration of the disease of 6.5 years (range from one to 20 years). The latency between the onset of focal injury and appearance of abnormal posturing was determined in 9 patients and ranged from a few days (Patient 3) to 3.5 years (Table 1). The patients were followed on average for 4 years.

Generalized dystonia was present in 3 patients, hemidystonia in 4 , segmental dystonia in 3 and focal dystonia in 6 (hand dystonia in 3 , blepharospasm in 2 , and oromandibular dystonia in one) (Table 1). The sites of onset of abnormal movements in cases with segmental dystonia were left hand with subsequent axial involvement in Patient 4, neck (head rotated to left) with dystonia spreading to the right, and later, to the left arm in Patient 5, while the initial torticollis (head rotated to left) in Patient 6 was followed by the development of oromandibular dystonia and bilateral blepharospasm.

The etiology of the lesions was infarction in 7 patients, tumor in 4, basal ganglia calcification in one patient with Morbus Sjögren, and also, vasculitis, cerebral anoxia due to cardiac arrest, trauma, and arterio-venous (A-V) malformation in one of each (Table 1).

Table 1: Clinical characteristics, localization and etiology of lesions in 16 patients with symptomatic dystonia.

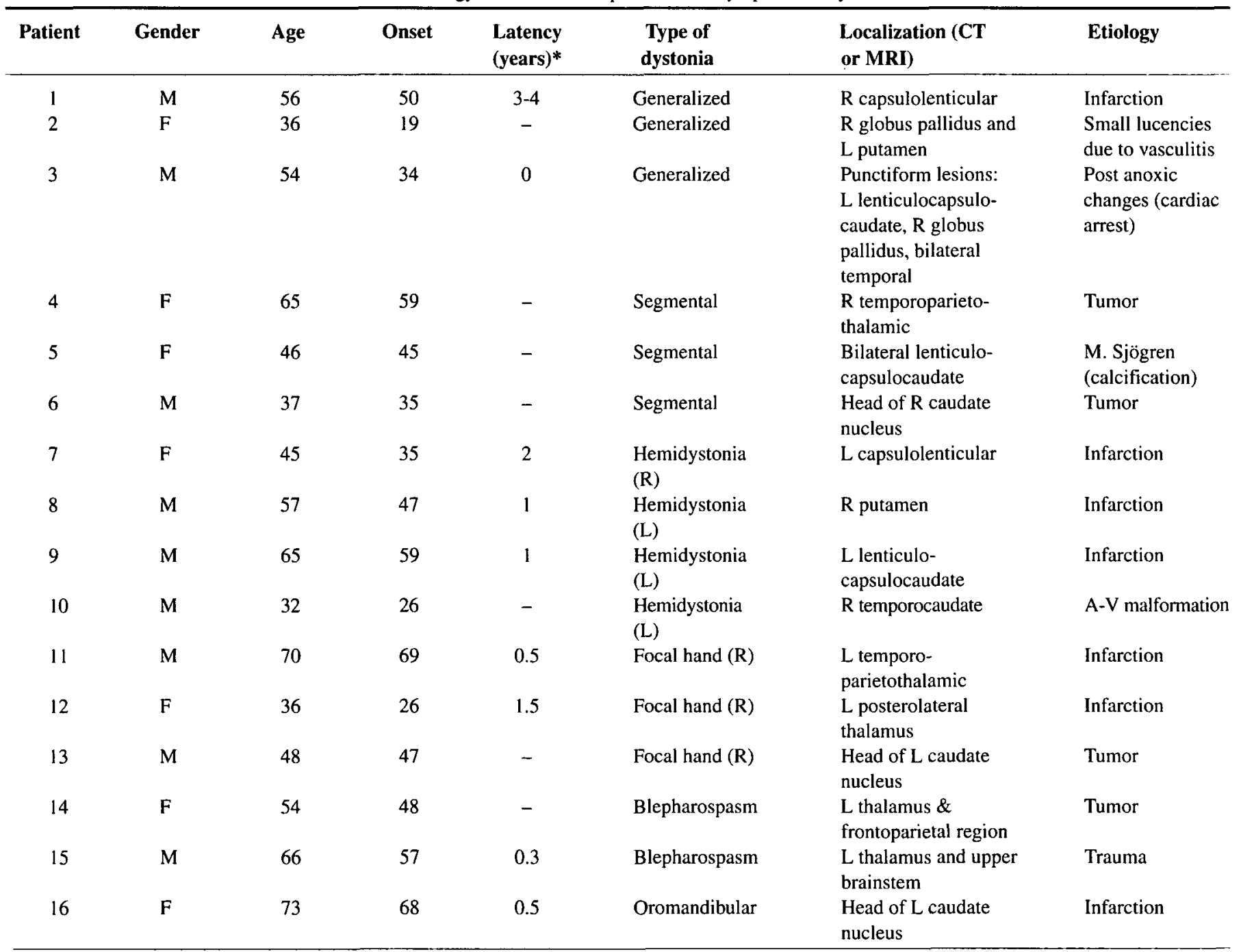

* - interval between onset of lesion and onset of dystonia;

- - unknown; R - right; L - left; F - female; $M$ - male 
Small, discrete lesions were observed in 6 patients (Patients $6,7,8,12,13$ and 16), mainly located in the head of caudate nucleus ( 3 patients), while larger lesions frequently affecting several brain structures were detected in 7 patients. In 3 patients multiple, punctiform lesions were found (Table 1).

The location of the lesions associated with dystonias secondary to anatomical involvement is tabulated in Table 2.

\section{Discussion}

The location of focal brain lesions associated with dystonia was described in 16 patients (Table 1). The caudate and lentiform nuclei, as well as thalamus, were, similarly to findings of the other authors, ${ }^{3-8}$ the most frequent sites of pathology (Table 2). On analyzing the behavioral and movement disorders in 240 patients described in the literature with focal lesions affecting the caudate nucleus, putamen and globus pallidus, Bhatia and Marsden ${ }^{5}$ found that dystonia was the most frequent movement disorder recorded (36\%). However, we found that in only 6 out of 16 patients (Patients 6,78, 12, 13 and 16) was dystonia associated with a discrete focal lesion of defined brain area or nuclei; in the other patients, multiple or relatively large lesions were observed. Three of the focal lesions were in caudate nucleus (Patient 6 with segmental dystonia, Patient 13 with focal hand dystonia and Patient 16 with oromandibular dystonia). Bhatia and Marsden reported ${ }^{5}$ that lesions of the caudate nucleus rarely caused motor disorders, with dystonia described in only $9 \%$ of such cases. Patient 12 with focal hand dystonia had posterolateral thalamic infarction. In the 33 patients with movement disorders following a lesion confined to the thalamus, Lee and Marsden" reported dystonia in 16 patients: 5 of them with a contralateral focal dystonia (all affecting the hand and/or arm).

It has been suggested that the lesions of different nuclei could cause different distribution of dystonia. ${ }^{9}$ However, the difficulty in distinguishing the boundaries of lesions affecting the globus pallidus and putamen in CT scans is well recognized. ${ }^{6}$ Studies dealing with dystonia secondary to a focal CNS lesion have mainly involved cases of hemidystonia or focal limb dystonia. ${ }^{4,6.10}$ In our series we report only 4 cases of hemidystonia (25\%). Hemidystonia has been related to large caudatocapsulolenticular lesions and also to small lesions in the putamen, $4,6,10$ although isolated cases associated with single lesions of caudate nucleus, ${ }^{4}$ posterolateral thalamus,,${ }^{4.9}$ globus pallidus, ${ }^{10}$ and parieto-occipital mass lesion" have been described. In 3 of our patients (Patients 7, 8 and 9) capsulolenticular, putaminal and lenticulocapsulocaudate infarctions were found (Table 1), all with history of a previous hemiparesis ("posthemiplegic dystonia"). ${ }^{4}$ Neuropathological examinations in 5 patients with "posthemiplegic athetosis" found striatal lesions in 4 , and generalized gliosis of the thalamus in one brain. ${ }^{12}$ Marsden et al. ${ }^{4}$ and Pettigrew and Jankovic ${ }^{10}$ on analyzing their cases with hemidystonia reported similar anatomical distribution of lesions: mainly contralateral striatum (particularly putamen), thalamus, or both. Even in a patient with hemidystonia and a normal CT, a functional study by Perlmutter and Raichle ${ }^{13}$ using positron emission tomography revealed an extensive contralateral increase in blood flow and decreased oxygen in the basal ganglia. Therefore, symptomatic dystonia may be produced by anatomic or functional disconnection of the thalamus from the striatum, resulting in abnormal thalamic-mediated input to premotor and mortor cortex..$^{4.10 .12} \mathrm{~A}$ parallel requirement for relative sparing of corticospinal tracts has been suggested by some authors, ${ }^{10.12}$ but questioned by others. ${ }^{8}$ In all of our 3 patients (Patients 7,8 and 9) dystonia appeared after hemiparesis had resolved. In one patient (Patient 10), an inoperable temporocaudate A-V malformation was related to contralateral hemidystonia and persisting hemiparesis; an etiology previously reported in symptomatic dystonia. ${ }^{4,14}$

Focal hand dystonia was observed in 3 patients (Table 1). In 2 of them (Patients 11 and 12), infarction of posterolateral thalamus was found, which is in accordance with the conclusion from previous studies that hand dystonia is mainly related to the lesions of this area, either alone or in combination with the caudate and/or lenticular lesions. ${ }^{4,6,15}$ However, symptomatic dystonia of the hand and arm was also, although infrequently, reported to be associated with isolated lesions of the lentiform, ${ }^{6,17}$ and of the caudate nucleus, ${ }^{18}$ as in our Patient 13, with a tumor affecting the head of caudate nucleus (Table 1).

Another 3 patients presented with segmental dystonia (Table 1). Jabbari et al. ${ }^{19}$ described a case of segmental axial dystonia with 3 focal areas of posttraumatic encephalomalacia, one involving the head of the left caudate nucleus. CT of our Patient 6 (Table 1), presented with craniocervical dystonia, disclosed an isolated lesion of the head of the right caudate nucleus. The patient with brachial segmental dystonia (Patient 5) had bilateral

Table 2: Distribution of lesion responsible for dystonia.

\begin{tabular}{|c|c|c|c|c|c|c|c|c|c|c|c|c|}
\hline \multirow[t]{2}{*}{$\begin{array}{l}\text { Type of } \\
\text { dystonia }\end{array}$} & \multicolumn{2}{|c|}{$\begin{array}{c}\text { Lentiform } \\
\text { nucleus }\end{array}$} & \multicolumn{2}{|c|}{$\begin{array}{l}\text { Caudate } \\
\text { nucleus }\end{array}$} & \multicolumn{2}{|c|}{ Thalamus } & \multicolumn{2}{|c|}{$\begin{array}{l}\text { Internal } \\
\text { capsule }\end{array}$} & \multicolumn{2}{|c|}{ Brainstem } & \multicolumn{2}{|c|}{ Cortex } \\
\hline & $S$ & $\mathrm{C}$ & $S$ & $\mathrm{C}$ & $S$ & $\mathrm{C}$ & $S$ & $\mathrm{C}$ & $S$ & $\mathrm{C}$ & $\mathrm{S}$ & $\mathrm{C}$ \\
\hline Segmental* & & & & & & & & & & & & \\
\hline -Neck & - & 1 & 1 & 1 & - & - & - & 1 & - & - & - & - \\
\hline- Arm & - & - & - & - & - & 1 & - & - & - & - & - & 1 \\
\hline Focal hand & - & - & 1 & - & 1 & 1 & - & - & - & - & - & 1 \\
\hline Blepharospasm & - & - & - & - & - & 2 & - & - & - & 1 & - & 1 \\
\hline Oromandibular & - & - & 1 & - & - & - & - & - & - & - & - & - \\
\hline
\end{tabular}

$\mathrm{S}$ - single lesion; C - combined lesion

* - Segmental dystonia was divided according to the site of onset of dystonia 
lenticulocapsulocaudate calcifications associated with Sjögren's syndrome: this entity with bilateral pallidal calcification was suggested as an etiology for Meige's syndrome. ${ }^{20}$ However, bilateral basal ganglia calcification is frequently asymptomatic, but in our patient dystonic movements correlate with the disease progression. In all 3 patients with segmental dysotnia, complete signs had developed in a course of 2-3 months, beginning as torticollis in 2 of them. Isolated cervical dystonia has been reported in association with an A-V malformation involving the caudate nucleus contralateral to the direction of neck rotation (as in our Patient 16), ${ }^{4}$ with lacunar infarctions in the contralateral putamen, ${ }^{21}$ with traumatic infarction in the contralateral caudate nucleus and putamen, ${ }^{22,23}$ with a midbrain lesion in a case of multiple sclerosis, ${ }^{24}$ and with a unilateral lesion in the centrum semiovale. ${ }^{25}$ The significance of basal ganglia injuries in secondary cervical dystonia has had recent support by the finding of prolonged MRI $\mathrm{T}_{2}$ times exclusively in the lentiform nucleus in idiopathic spasmodic torticollis. ${ }^{26}$

Blepharospasm secondary to structural focal lesions had been described in very few cases, mainly including the lesions of upper brainstem ${ }^{6.27 .28}$ and, to a lesser degree, bilateral basal ganglia lesions. ${ }^{29-31}$ An upper brainstem lesion was present in our Patient 15; in our Patient 14, a large tumorous mass primarily' affecting left thalamus and frontoparietal region was found which might also result in brainstem compression and damage. ${ }^{32}$ Even less information is available for the other forms of cranial dystonia, suggesting that the mesodiencephalic region is likely to be their main morphological basis. We report a case with oromandibular dystonia (Patient 16) associated with unilateral infarction of the head of caudate nucleus (Table 1).

Cases with generalized dystonia secondary to bilateral basal ganglia lesions have been occasionally reported. ${ }^{33-36}$ This is similar to our Patients 2 and 3, due to vasculitis and severe anoxia, respectively. However, in Patient 1 generalized dystonia was associated with unilateral capsulolenticular infarction, although, considering the sensitivity of CT, we could not exclude the existence of small, lacunar infarctions in contralateral structures.

In conclusion, progress in neuroimaging techniques had made it possible to investigate cases of secondary dystonia. Our own experience with 16 patients extends previous efforts to provide a pathological and physiological understanding for cases with idiopathic dystonia.

\section{ACKNOWLEDGEMENT}

The authors want to thank Mrs. Vesna Kostic and Dr. Nir Giladi for helping them prepare the manuscript.

\section{REFERENCES}

1. Fahn S, Marsden CD, Calne D. Classification and investigation of dystonia. In: Marsden CD, Fahn S, eds. Movement Disorders 2. London: Butterworths, 1987: 1-4.

2. Rajput AH, Gibb WRG, Zhong XH, et al. Dopa-responsive dystonia: pathological and biochemical observations in a case. Ann Neurol 1994; 35: 396-402.

3. Rothwell JC, Obeso JA. The anatomical and physiological basis of torsion dystonia. In: Marsden CD, Fahn S, eds. Movement Disorders 2. London: Butterworths, 1987: 313-331.

4. Marsden CD, Obeso JA, Zarranz JJ, Lang AE. The anatomical basis of symptomatic hemidystonia. Brain 1985; 108: 463-483.

5. Bhatia KP, Marsden CD. The behavioural and motor consequences of focal lesions of the basal ganglia in man. Brain 1994; 117 : 859-876

6. Obeso JA, Gimenez-Roldan S. Clinicopathological correlation in symptomatic dystonia. Adv Neurol 1988; 50: 113-122.
7. Burton K, Farrell K, Li D, Calne D. Lesions of the putamen and dystonia: CT and magnetic resonance imaging. Neurology 1984; 34: 962-965.

8. Factor SA, Sanchez-Ramos J, Weiner WJ. Delayed-onset dystonia associated with corticospinal tract dysfunction. Movement Dis 1988; 3: 201-210.

9. Lee MS, Marsden CD. Movement disorders following lesions of the thalamus or subthalamic regions. Movement Dis 1994; 9 : 492-507.

10. Pettigrew LC, Jankovic J. Hemidystonia: a report of 22 patients and a review of literature. J Neurol Neurosurg Psychiatry 1985; 48: 650-657

11. Krauss JK, Mohadier M, Nobbe F, Scheremet R. Hemidystonia due to a contralateral parieto-occipital metastasis: disappearance after removal of the mass lesion. Neurology 1991; 41: 1519. 1520.

12. Dooling EC, Adams RD. The pathological anatomy of posthemiplegic athetosis. Brain 1975; 98: 29-48.

13. Perlmutter JS, Raichle ME. Pure hemidystonia with basal ganglia abnormalities on positron emission tomography. Ann Neurol 1984; 15: 228-233.

14. Friedman DI, Jankovic J, Rolak LA. Arteriovenous malformation presenting as hemidystonia. Neurology 1986; 26: 1590-1593.

15. Tolge CF, Factor SA. Focal dystonia secondary to cerebral toxoplasmosis in a patient with acquired immune deficiency syndrome. Movement Dis 1991; 6: 69-72.

16. Russo LS. Focal dystonia and lacunar infarction of the basal ganglia: a case report. Arch Neurol 1983; 40: 61-62.

17. Lorenzana L, Caberuda JM, Porras LF, et al. Focal dystonia secondary to cavernous angioma of the basal ganglia: case report and review of the literature. Neurosurgery 1992; 31: 1108-1112.

18. Messimy R, Diebler C, Metzger J. Dystonie de torsion du membre superieur gauche probalement consecutive as un traumatisme cranien. Rev Neurol 1977; 133: 199-206.

19. Jabbari B, Paul J, Scherokman B, Van Dam B. Posttraumatic seg. mental axial dystonia. Movement Dis 1992; 7: 78-81.

20. Herraiz J, Roquer J, Escudero D, Maso E. Meige's syndrome and bilateral pallidal calcification. J Neurol 1988; $235: 384$.

21. Molho ES, Factor SA. Basal ganglia infarction as a possible cause of cervical dystonia. Movement Dis 1993; 8: 213-216.

22. Maki Y, Akimoto H, Enomoto I. Injuries of basal ganglia following head trauma in children. Childs Brain 1980; 7: 113-123.

23. Isaac K, Cohen JA. Post-traumatic torticollis. Neurology 1989; 39: 1642-1643.

24. Plant GT, Kermode AG, du Boulay EPGH, McDonald WI. Spasmodic torticollis due to a midbrain lesion in a case of multiple sclerosis. Movement Dis 1989; 4: 359-362.

25. Biary N, Al Deeb SM, Aabed M. Post-traumatic dystonia. Ann Neurol 1991; 30: 297

26. Schneider S, Feifel E, Oh D, et al. Prolonged MRI $T_{2}$ times of the lentiform nucleus in idiopathic spasmodic torticollis. Neurology 1994; 44: 846-850.

27. Jankovic J, Patel SC. Blepharospasm associated with brainstem lesions. Neurology 1983; 33: 1237-1240.

28. Powers JM. Blepharospasm due to unilateral diencephalic infarction. Neurology 1985; 35: 283-284.

29. Keane $: J R$, Young JA. Blepharospasm with bilateral basal ganglia infarction. Arch Neurol 1985; 42: 1206-1208.

30. Jankovic J. Blepharospasm with basal ganglia lesions. Arch Neurol 1986; 43: 866-868.

31. Larumbe R, Vaamonde J, Artieda J, Zubieta JL, Obeso JA. Reflex blepharospasm associated with bilateral basal ganglia lesion. Movement Dis 1993; 8: 198-200.

32. Gatto M, Micheli F, Pardal MF, Blepharoclonus and parkinsonism associated with aqueductal stenosis. Movement Dis 1990; 5: 310-313.

33. Denny-Brown D. The Basal Ganglia and Their Relation to Disorders of Movement. London: Oxford University Press, 1962.

34. Campistol J, Cusi V, Vernet A, et al. Dystonia as a presenting sign of subacute necrotising encephalomyelopathy in infancy. Eur $\mathrm{J}$ Pediatr 1986; 144: 589-591.

35. Hawker K, Lang AE. Hypoxic-ischemic damage of the basal ganglia. Movement Dis 1990; 5: 219-224.

36. Iwata M. MRI Pathology of basal ganglia in dystonic disorders. Adv Neurol 1993; 60: 535-539. 